Vol. 1 No. 1, Maret 2021, hlm. $81-88$

DOI: $\operatorname{xxxxxxxxxxxxxxxxx}$

Available online at http:// jurnal.stmikroyal.ac.id/index.php/j-com

\title{
SISTEM PENDUKUNG KEPUTUSAN UNTUK MENENTUKAN SANKSI PELANGGARAN SISWA MENGGUNAKAN METODE TOPSIS
}

\author{
Rita Ratna Sari ${ }^{1}$, Nurwati ${ }^{2 *}$,Elly Rahayu ${ }^{3}$ \\ ${ }^{1}$ Mahasiswa Prodi Sistem Informasi, STMIK Royal \\ ${ }^{2}$ Prodi Teknik Komputer, STMIK Royal \\ ${ }^{3}$ Prodi Sistem Informasi, STMIK Royal \\ "email: nurwati763@gmail.com
}

\begin{abstract}
All students in the world of education in the learning process are not separated from the various rules and regulations that apply or are implemented by the school and it is mandatory to be obeyed by every student. With this, it is intended that every student knows about discipline. At SMP Negeri 1 Bosar Maligas presence, tidiness, personality and order are aspects of discipline which are used as references to measure the level of student discipline. The mechanism for measuring the level of discipline of each student is measured manually, namely by accumulating points of violations committed by students, then determining the sanctions that will be given. The purpose of this study is to analyze and design a decision support system to determine the level of discipline and sanctions for student violations using the TOPSIS (Technique Order Preference by Similarity To Ideal Solution) method and implement the system to assist counseling teachers in monitoring student discipline levels, and can be effective and efficiently find the number of points of violation committed by students. The system is designed using the MySQL database, PHP programming language, and Macromedia Dreamweaver application software.
\end{abstract}

Keywords: Discipline, TOPSIS, Macromedia Dreamweaver, Hypertext PrePocessor, Decision Support Systems.

\begin{abstract}
Abstrak: Semua siswa di dalam dunia pendidikan dalam proses belajar tidak ada yang terlepas dari berbagai tata tertib dan peraturan yang berlaku atau di jalankan oleh sekolah dan memang wajib harus di taati oleh setiap siswa. Dengan adanya hal tersebut bertujuan supaya setiap siswa mengetahui tentang kedisiplinan. Di SMP Negeri 1 Bosar Maligas kehadiran, kerapian, kepribadian dan ketertiban merupakan aspek kedisiplinan yang dijadikan sebagai acuan untuk mengukur tingkat kedisiplinan siswa. Mekanisme pengukuran tingkat disiplin dari masingmasing siswa diukur dengan cara manual, yaitu dengan mengakumulasi point pelanggaran yang dilakukan siswa, kemudian ditentukan sanksi yang akan diberikan. Tujuan dari penelitian ini untuk menganalisis dan merancang sistem pendukung keputusan untuk menentukan tingkat kedisiplinan dan sanksi pelanggaran siswa menggunakan metode TOPSIS (Technique Order Preferenceby Similarity ToIdeal Solution) dan mengimplementasikan sistem tersebut untuk membantu guru BK dalam memantau tingkat kedisiplinan siswa, dan dapat dengan efektif dan efesien mencari jumlah point pelanggaran yang di lakukan oleh siswa.Sistemdi rancang menggunakan database MySQL,bahasa pemrograman PHP, dan software aplikasi macromedia dreamweaver.
\end{abstract}

Kata Kunci :Kedisiplinan, TOPSIS, Macromedia Dreamweaver, PHP, Sistem Pendukung Keputusan. 
Vol. 1 No. 1, Maret 2021, hlm. $81-88$

DOI: $\operatorname{xxxxxxxxxxxxxxxxx}$

Available online at http:// jurnal.stmikroyal.ac.id/index.php/j-com

\section{PENDAHULUAN}

Usaha yang harus di lakukan dalam membentuk karakter siswa di dalam dunia pendidikan sangat di butuhkan adanya suatu kedisiplinan yang berguna untuk membentuk karakter sebagai proses membentuk siswa yang memiliki pemahaman diri yang sesuai dengan kepribadian yang di miliki oleh masing-masing siswa yang dapat di lihat dalam hasil belajar mereka masing - masing.

Tujuan dari kedisiplinan, yaitu terbangunnya dan terpeliharanya sikap perilaku yang baik dan bertanggung jawab dari anak dalam mematuhi semua peraturan yang berlaku di sekolah, dengan begitu maka proses pembelajaran menjadi efektif dan efisien sehingga anak mampu memiliki hasil atau prestasi yang baik dan bisa dibanggakan.Semua pelajar atau siswa dalam proses mengikuti belajar disekolah semua terikat dari berbagai peraturan dan tata tertib yang ada dan wajib setiap siswa harus mematuhinya. Hal tersebut di buat supaya siswa memiliki pemahaman dan maksud tujuan dari kedisiplinan.

Kedisiplinan adalah suatu kebijakan yang ada atau di berlakukan dalam suatu instansi yang harus di patuhi semua peraturannya oleh setiap orang yang ada di dalamnya. Disiplin menurut pandangan secara umum diartikan sebagai suatu proses menyesuaikan diri dengan lingkungan sosial dengan cara mengendalikan diri pribadi. Dalam lingkup pendidikan, disiplin akan memudahkan kelancaran segala kegiatan dan disiplin mampu menjadi kunci sukses bagi seseorang [1].

Banyaknya siswa yang tidak mematuhi dan melakukan pelanggaran terhadap peraturan yang ada di sekolah seperti, melawan guru, mengganggu teman, merokok di dalam kamar mandi, dan sering tidak sekolah dan malas belajar membuat keadaan sekolah dan juga kelas menjadi tidak nyaman. Sehingga pihak sekolah mengalami kesulitan dalam menangani masalah - masalah yang ada di sekolah dan bingung menentukan sanksi dan jumlah point pelanggaran yang di lakukan oleh siswa.

Dari berbagai masalah siswa tersebut guru BK SMP Negeri 1 Bosar Maligas masih menggunakan sistem manual dengan cara mencatat seluruh kejadian atau masalah ke dalam buku dalam proses perhitungan point pelanggaran siswa dalam menentukan sanksi pelanggaran. Oleh karena itu sekolah ingin merancang sebuah sistem pendukung keputusan yang dapat membantu guru dalam menangani permasalahan pelanggaran siswa ini.

Sistem pendukung keputusan yang digunakan oleh guru bimbingan konseling SMP Negeri 1 Bosar Maligas sangatlah tidak efektif dan efisien karena hal ini membuat proses yang sangat lama untuk mengevaluasi tingkat kedisiplinan siswa dan menentukan point sanksi pelangggaran yang di lakukan oleh siswa. Banyaknya siswa yang melanggar peraturan membuat SMP Negeri 1 Bosar Maligas sangat memerlukan adanya suatu sistem yang mampu mempermudah atau meringankan tugas guru bimbingan konseling yang bisa membantu dalam mengelola point pelanggaran atau data skorsing siswa yang dapat peroleh hasilnya dengan cepat. Dengan begitu guru bimbingan konseling dapat dengan mudah untuk dapat mengetahui jumlah point pelanggaran dan sanksi tindakan yang didapat selama belajar di SMP Negeri 1 Bosar Maligas. Harapannya dengan mengetahui point pelanggaran yang dilakukan, siswa dapat memperbaiki perilakunya dan taat terhadap peraturan yang di buat sehingga kedisiplinan pada setiap siswa dapat meningkat. 
Vol. 1 No. 1, Maret 2021, hlm. $81-88$

DOI: $\mathrm{xxxxxxxxxxxxxxxxx}$

Available online at http:// jurnal.stmikroyal.ac.id/index.php/j-com

Perancangan sistem ini di buat menggunakan metode TOPSIS (Technique For Others Reference by Similarity to Ideal Solution) yang merupakan sebuah metode yang di gunakan dalam pengambilan keputusan yang dapat membantu pihak sekolah dalam menentukan kebijakan yang telah di buat, pengambilan keputusanyang menggunakan kriteria yang sederhana, sehingga mudah di mengerti dan di pahami dan memiliki kemampuan yang baik untuk mengetahui nilai dari alternatif-alternatif keputusan dalam bentuk matematis yang sederhana

\section{METODE}

\section{Sistem Pendukung Keputusan}

Merupakan suatu sistem informasi yang menggunakan model-model keputusan, basisdata, dan pemikiran manajer sendiri, proses modelling interaktif dengan komputer untuk mencapai pengambilan keputusan oleh manajer tertentu. dan dapat digunakan untuk memberikan perangkat yang interaktif dan memungkinkan untuk melakukan berbagai analisis dari model yang tersedia [2].

Tujuan penggunaan Sistem Pendukung Keputusan adalah Membantu manajer untuk mengambil suatu keputusan atas masalah semi terstrukur, memberi dukungan atas pertimbangan manajer dan tidak untuk menggantikan fungsi manajer, dalam berdaya saing, peningkatan produktivitas [3].

\section{Konsep Dasar Penggunaan TOPSIS}

Berikut merupakan langkah-langkah proses TOPSIS yaitu: (1) Membuat Matriks Keputusan Ternormalisasi., (2) Membuat matriks keputusan yang ternormalisasi terbobot., (3) Menentukan matriks solusi ideal positif \& matriks solusi ideal negatif., (4) Menentukan jarak antara nilai setiap alternatif dengan matriks solusi ideal positif \& matriks solusi ideal negatif., (5) Menentukan nilai preferensi untuk setiap alternatif [4].

Penggunaan Metode TOPSIS dapat disimpulkan sebagai berikut: (1) Perhitungan Matriks Keputusan Ternormalisasi persamaan (1):

$$
r_{i j=} \underline{x_{i j}} \sqrt{\sum_{\mathrm{i}=1}^{2}}
$$

Keterar

$\mathrm{r}$ : Matriks keputusan ternormalisasi

i : $1,2, \ldots \ldots, \mathrm{m}$

$\mathrm{m}$ : Menunjukkan jumlah alternatif yang dievalusasi

$\mathrm{x}_{\mathrm{ij}}$ : Menunjukkan nilai rating kecocokan alternatif ke $-\mathrm{i}$ terhadap kriteria ke -j [5]. 
DOI: $\mathrm{xxxxxxxxxxxxxxxxx}$

Available online at http:// jurnal.stmikroyal.ac.id/index.php/j-com

(2) Perhitungan matriks keputusan yang ternormalisasi terbobot dalam persamaan (2):

$\boldsymbol{Y}=\boldsymbol{R} \boldsymbol{x} \boldsymbol{W}$

Keterangan:

$\boldsymbol{Y} \quad$ : Matriks keputusan ternormalisasi terbobot

$\boldsymbol{R} \quad$ : Nilai dari masing - masing data ternormalisasi

$\boldsymbol{W}$ : Nilai Bobot

(3) Menentukan matriks solusi ideal positif (A+) dan Negatif (A-) (3):
$\mathrm{A}+=(\mathrm{y} 1+, \mathrm{y} 2+, \ldots \ldots, \mathrm{yn}+)$
$\mathrm{A}-=(\mathrm{y} 1-, \mathrm{y} 2-, \ldots . . ., \mathrm{yn}-)$
Keterangan:
$y_{i}^{+}=\left\{\begin{array}{c}\text { maxyij : jikaj adalah atribut keuntungan } \\ \text { min yij }: \text { jika } j \text { adalah atribut biaya }\end{array}\right.$
$y_{i}^{-}=\left\{\begin{array}{c}\max y i j: \text { jika j adalah atribut biaya } \\ \text { minyij : jikaj adalah atribut keuntungan }\end{array}\right.$

(4) Menentukan jarak antara nilai setiap alternatif dengan matriks solusi ideal positif \& matriks solusi ideal negatif

$\left.D_{i}^{+}=\sqrt{\sum_{i=1}^{n}\left(y_{i}^{+}\right.}-y_{i j}\right)^{2}$

Keterangan :

D : Jarak solusi ideal positif/negatif

$y_{j}^{+}$: Solusi ideal positif untuk atribut $\mathrm{ke}-\mathrm{j}$

$y_{I_{j}}$ : Elemen dari matrikskeputusan yang ternormalisasi terbobot Y

$y_{j}^{-}$: Solusi ideal negatif untuk atribut $\mathrm{ke}-\mathrm{j}$

i $: 1,2, \ldots \ldots \ldots, \mathrm{m}$

$\left.D_{i}^{-}=\sqrt{\sum_{i=1}^{n}(y i j-} y_{j}^{-}\right)^{2}$

Keterangan :

D : Jarak solusi ideal positif/negatif

$y_{j}^{+}$: Solusi ideal positif untuk atribut ke $-\mathrm{j}$

$y_{I^{f}}$ : Elemen dari matrikskeputusan yang ternormalisasi terbobot $\mathrm{Y}$

$y_{j}^{-}$: Solusi ideal negatif untuk atribut ke $-\mathrm{j}$

i $: 1,2, \ldots ., \mathrm{m}$

(5) Perhitungan nilai preferensi ( $V_{i}$ untuk setiap alternatif

$V_{i}=\frac{D_{i}^{-}}{D_{i}^{-}+D_{i}^{+}}$

Keterangan :

$\mathbf{V}_{\mathbf{i}}=$ Nilai preferensi untuk setiap alternatif

Nilai $V_{i}$ yang lebih besar menunjukkan bahwa alternatif $A_{i}$ lebih dipilih. 
Vol. 1 No. 1, Maret 2021, hlm. $81-88$

DOI: $\mathrm{xxxxxxxxxxxxxxxxx}$

Available online at http:// jurnal.stmikroyal.ac.id/index.php/j-com

\section{HASIL PEMBAHASAN}

Berdasarkan permasalahan yang ada, perhitungan point pelanggaran siswa akan dibuat dengan sistem yang lebih baik. Guru BK dalam menghitung skorsing point pelanggaran siswa dapat dengan cepat dan efisien dengan menggunakan sistem pendukung keputusan yang berbasis komputer berdasarkan Kriteria, Bobot kriteria dan penilaian yang telah ditetapkan. Dengan adanya Perhitungan point pelanggaran siswa yang dibuat makadi harapkan murid dapat memperbaiki tingkah laku dan meningkatkan kedisiplinan di sekolah. Kriteria, Bobot Kriteria dan Penilaian terhadap Alternatif akan diurutkan berdasarkan prioritas kepentingan faktor yang telah ditetapkan kemudian akan diberi Nilai Pembobotan Kriteria yaitu sebagai berikut ini:

Tabel 1. Criteria

\begin{tabular}{|c|c|c|}
\hline No. & Criteria & Kode Criteria \\
\hline 1. & Kehadiran & C1 \\
\hline 2. & Kerapian & C2 \\
\hline 3. & Kepribadian & C3 \\
\hline 4. & Ketertiban & C4 \\
\hline
\end{tabular}

Tabel 2. Bobot Criteria

\begin{tabular}{|c|c|c|c|}
\hline No & Kode & Faktor & Nilai Bobot \\
\hline 1 & C1 & Kehadiran & 5 \\
\hline 2 & C 2 & Kerapian & 2 \\
\hline 3 & C3 & Kepribadian & 3 \\
\hline 4 & C 4 & Ketertiban & 4 \\
\hline
\end{tabular}

Tabel 3. Range Criteria Penilaian

\begin{tabular}{|c|c|c|}
\hline Rentang Nilai & Point & Keterangan \\
\hline $0-59$ & 1 & Sangat buruk \\
\hline $60-69$ & 2 & Buruk \\
\hline $70-79$ & 3 & Cukup \\
\hline $80-89$ & 4 & Baik \\
\hline $90-100$ & 5 & Sangat Baik \\
\hline
\end{tabular}

Setelah dilakukan pembobotan, nama siswa yang tercantum akan diberikan bobot kriteria berdasarakan Range kriteria penilaian untuk setiap kriteria yang disebut dengan evaluasi faktor, seperti terlihat pada tabel berikut ini:

Tabel 4. Data Awal dari Pembobotan Alternatif

\begin{tabular}{|c|c|l|c|c|c|c|}
\hline Alternatif & NIS & \multicolumn{1}{|c|}{ Nama Siswa } & C1 & C2 & C3 & C4 \\
\hline A1 & 4833 & Afriza Fahrenza & 90 & 55 & 55 & 55 \\
\hline A2 & 4835 & Arya Bayu Nata & 87 & 56 & 68 & 68 \\
\hline A3 & 4845 & Davin Ramadhan & 85 & 55 & 55 & 75 \\
\hline A4 & 4850 & Dika Fahri Febrian & 90 & 80 & 75 & 55 \\
\hline A5 & 4851 & Diki Fransisko Sirait & 90 & 55 & 58 & 56 \\
\hline A6 & 5007 & Paulus Butar-butar & 90 & 55 & 56 & 67 \\
\hline
\end{tabular}


Vol. 1 No. 1, Maret 2021, hlm. $81-88$

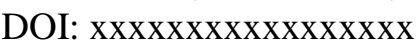

Available online at http:// jurnal.stmikroyal.ac.id/index.php/j-com

Tabel 5. Data Pembobotan Alternatif

\begin{tabular}{|c|c|c|c|c|c|c|c|c|}
\hline \multirow[b]{2}{*}{$\begin{array}{l}\text { Ko } \\
\text { de }\end{array}$} & \multirow[b]{2}{*}{ Criteria } & \multicolumn{6}{|c|}{ Alternatif } & \multirow[b]{2}{*}{$\begin{array}{c}\text { JumlahPe } \\
\text { mbagi }\end{array}$} \\
\hline & & A1 & A2 & A3 & A4 & A5 & A6 & \\
\hline $\mathrm{C} 1$ & Kehadiran & 5 & 4 & 4 & 5 & 5 & 5 & 11,49 \\
\hline $\mathrm{C} 2$ & Kerapian & 1 & 1 & 1 & 4 & 1 & 1 & $\mathbf{4 , 5 8}$ \\
\hline C3 & Kepribadian & 1 & 2 & 1 & 3 & 1 & 1 & 4,12 \\
\hline$\overline{\mathrm{C} 4}$ & Ketertiban & 1 & 2 & 3 & 1 & 1 & 2 & 4,47 \\
\hline
\end{tabular}

Tabel 6. Matriks Keputusan Ternormalisasi

\begin{tabular}{|c|c|l|c|c|c|c|}
\hline \multirow{2}{*}{$\begin{array}{c}\text { Alternat } \\
\text { if }\end{array}$} & \multirow{2}{*}{ NIS } & \multirow{2}{*}{ Nama Siswa } & \multicolumn{4}{|c|}{ Kriteria } \\
\cline { 4 - 7 } & & & C1 & C2 & C3 & C4 \\
\hline A1 & 4833 & Afriza Fahrenza & 0,44 & 0,22 & 0,24 & 0.22 \\
\hline A2 & 4835 & Arya Bayu Nata & 0,35 & 0,22 & 0,49 & 0,45 \\
\hline A3 & 4845 & Davin Ramadhan & 0,35 & 0,22 & 0,24 & 0,67 \\
\hline A4 & 4850 & Dika Fahri Febrian & 0,44 & 0,87 & 0,73 & 0,22 \\
\hline A5 & 4851 & Diki Fransisko Sirait & 0,44 & 0,22 & 0,24 & 0,22 \\
\hline A6 & 5007 & Paulus Butar-butar & 0,44 & 0,22 & 0,24 & 0,45 \\
\hline
\end{tabular}

Tabel 7. Matriks Keputusan Ternormalisasi Terbobot

\begin{tabular}{|c|c|c|c|c|c|c|}
\hline \multirow{2}{*}{ Alternatif } & \multirow{2}{*}{ NIS } & \multirow{2}{*}{ Nama Siswa } & \multicolumn{4}{|c|}{ Kriteria } \\
\cline { 4 - 7 } & & & C1 & C2 & C3 & C4 \\
\hline A1 & 4833 & Afriza Fahrenza & 2,18 & 0,44 & 0,73 & 0,89 \\
\hline A2 & 4835 & Arya Bayu Nata & 1,74 & 0,44 & 1,46 & 1,79 \\
\hline A3 & 4845 & Davin Ramadhan & 1,74 & 0,44 & 0,73 & 2,68 \\
\hline A4 & 4850 & Dika Fahri Febrian & 2,18 & 1,75 & 2,18 & 0,89 \\
\hline A5 & 4851 & Diki Fransisko Sirait & 2,18 & 0,44 & 0,73 & 0,89 \\
\hline A6 & 5007 & Paulus Butar-butar & 2,18 & 0,44 & 0,73 & 1.79 \\
\hline
\end{tabular}

Tabel 8. Matriks Solusi Ideal Positif \& Matriks Solusi Ideal Negatif

\begin{tabular}{|c|c|c|c|c|}
\hline $\mathrm{Y}+$ & 1,74 & 0,44 & 0,73 & 0,89 \\
\hline $\mathrm{Y}-$ & 2,18 & 1,75 & 2,18 & 2,68 \\
\hline
\end{tabular}

Menentukan Jarak antara nilai setiap alternatif dengan matriks solusi ideal positif \& matriks solusi ideal negatif.

$$
\left.D_{i}^{+}=\sqrt{\sum_{i=1}^{n}\left(y_{i}^{+}\right.}-y_{i j}\right)^{2}
$$

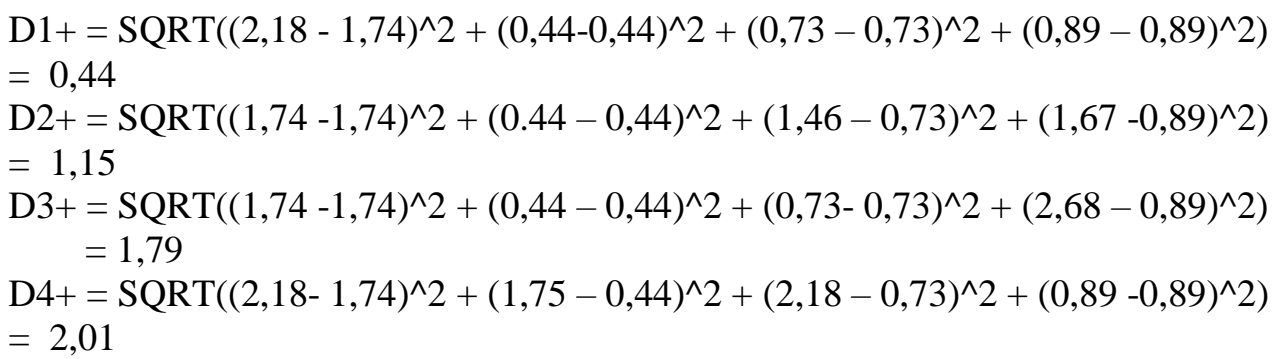


Vol. 1 No. 1, Maret 2021, hlm. $81-88$

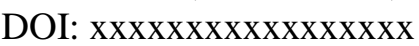

Available online at http:// jurnal.stmikroyal.ac.id/index.php/j-com

$\mathrm{D} 5+=\operatorname{SQRT}\left((2,18-1,74)^{\wedge} 2+(0,44-0,44)^{\wedge} 2+(0,73-0,73)^{\wedge} 2+(0,89-0,89)^{\wedge} 2\right)$

$=0,44$

D6+= SQRT $\left((2,18-1,74)^{\wedge} 2+(0,44-0,44)^{\wedge} 2+(0,73-0,73)^{\wedge} 2+(1,79-0,89)^{\wedge} 2\right)$

$=0.99$

Menghitung jarak antara nilai setiap alternatif dengan matriks solusi ideal negative dapat mengunakan rumus sebagai berikut :

$$
\left.D_{i}^{-}=\sqrt{\sum_{i=1}^{n}(y i j-} y_{j}^{-}\right)^{2}
$$

D1 - = SQRT $\left((2,18-2,18)^{\wedge} 2+(0,44-1,75)^{\wedge} 2+(0,73-2,18)^{\wedge} 2+(0,89-2,68)^{\wedge} 2\right)$

$=2,65$

$\mathrm{D} 2-=\mathrm{SQRT}\left((1,74-2,18)^{\wedge} 2+(0,44-1,75)^{\wedge} 2+(1,46-2,18)^{\wedge} 2+(1,79-2,68)^{\wedge} 2\right)$

$=1,80$

D3- = SQRT $\left((1,74-2,18)^{\wedge} 2+(0,44-1,75)^{\wedge} 2+(0,73-2,18)^{\wedge} 2+(2,68-2,68)^{\wedge} 2\right)$

$=2,01$

D4- = SQRT $\left((2,18-2,18)^{\wedge} 2+(1,75-1,75)^{\wedge} 2+(2,18-2,18)^{\wedge} 2+(0,89-2,68)^{\wedge} 2\right)$

$=1,79$

$\mathrm{D} 5-=\mathrm{SQRT}\left((2,18-2,18)^{\wedge} 2+(0,44-1,75)^{\wedge} 2+(0,73-2,18)^{\wedge} 2+(0,89-2,68)^{\wedge} 2\right)$

$=2,65$

D6- $=\operatorname{SQRT}\left((2,18-2,18)^{\wedge} 2+(0,44-1,75)^{\wedge} 2+(0,73-2,18)^{\wedge} 2+(1,79-2,68)^{\wedge} 2\right)$

$=2,15$

Tabel 9. Nilai Preferensi untuk setiap alternatif

\begin{tabular}{|c|c|c|}
\hline Alternatif & Nama Siswa & Preferensi \\
\hline A1 & Afriza Fahrenza & 0,85 \\
\hline A2 & Arya Bayu Nata & 0,60 \\
\hline A3 & Davin Ramadhan & 0,52 \\
\hline A4 & Dika Fahri Febrian & 0,47 \\
\hline A5 & Diki Fransisko Sirait & 0,85 \\
\hline A6 & Paulus Butar-butar & 0,68 \\
\hline
\end{tabular}

Tabel 10. Sanksi

\begin{tabular}{|l|l|}
\hline \multicolumn{1}{|c|}{ Sanksi } & \multicolumn{1}{c|}{ Point } \\
\hline Dipanggil Orangtua & $0-0,25$ \\
\hline Dipanggil Orangtua dan Skor 3 Hari & $0,26-0,50$ \\
\hline Dipanggil Orangtua dan Skor 6 Hari & $0,51-0,75$ \\
\hline Dipanggil Orangtua dan Dikeluarkan Dari Sekolah & $0,76-1,00$ \\
\hline
\end{tabular}

\section{SIMPULAN}

Berdasarkan hasil penelitian dan pengamatan sistem pendukung keputusan menggunakan metode topsis untuk menentukan tingkat kedisiplinan dan sanksi pelanggaran siswa SMP Negeri 1 Bosar Maligas dapat diambil beberapa kesimpulan: (1) Sistem pendukung keputusan yang di rancang akan mempermudah guru bimbingan konseling dalam menghitung point skorsing data pelanggaran siswa., (2) Sistem ini di 
Vol. 1 No. 1, Maret 2021, hlm. $81-88$

DOI: $\operatorname{xxxxxxxxxxxxxxxxx}$

Available online at http:// jurnal.stmikroyal.ac.id/index.php/j-com

rancang menggunakan algoritma Topsis sehingga dapat digunakan sebagai metode dalam pengambilan keputusan yang lebih baik karena perhitungan komputasinya lebih efisien dan cepat., (3) Sistem yang di rancang akan di jadikan salah satu perangkat pendukung pada SMP Negeri 1 Bosar Maligas.

\section{DAFTAR PUSTAKA}

[1] Handayani and U. Fadlilah, "Sistem Pendukung Keputusan untuk Menentukan Tingkat Kedisiplinan dan Sanksi Pelanggaran Siswa," J. Chem. Inf. Model., vol. 53, no. 9, pp. 1689-1699, 2019.

[2] T. Mardiana, "Penerapan Algoritma TOPSIS Dalam Sistem Pendukung Keputusan Pemberian Pinjaman pada Koperasi Karyawan," J. Khatulistiwa Inform., vol. 5, no. Vol 5, No 2 (2017): Periode Desember 2017, pp. 128-138, 2017.

[3] F. tr and A. Fadjar Siddiq Sistem Pendukung Keputusan Menggunakan Metode, "Sistem Pendukung Keputusan Menggunakan Metode Technique for Order by Similarity to Ideal Solution (TOPSIS)," Konf. Nas. Teknol. Inf. dan Apl., pp. 3337, 2011.

[4] A. Suryana, E. Yulianto, and K. D. Pratama, "Perancangan Sistem Pendukung Keputusan Penilaian Prestasi Pegawai Menggunakan Metode Saw, Ahp, Dan Topsis," J. Ilm. Teknol. Inf. Terap., vol. 3, no. 2, pp. 130-139, 2017, [Online]. Available: http://jitter.widyatama.ac.id/index.php/jitter/article/view/216.

[5] Sriani and R. A. Putri, "Analisa Sistem Pendukung Keputusan Mengunakan Metode TOPSIS Untuk Sistem Penerimaan Pegawai Pada SMA Al Washliyah Tanjung Morawa," J. Ilmu Komput. dan Inform., vol. 02, no. April, pp. 40-46, 2018. 